\title{
Optimalisasi peran mahasiswa melalui kuliah kerja nyata mandiri sebagai upaya mendukung pencegahan penularan Covid-19 pada masyarakat
}

\author{
Ika Pasca Himawati*, Heni Nopianti, \& Diyas Widiyarti \\ Fakultas Ilmu Sosial dan Ilmu Politik, Universitas Bengkulu \\ *ikapasca@unib.ac.id
}

\begin{abstract}
Abstrak. Pandemi Covid-19 telah memberikan berbagai perubahan di segala bidang kehidupan. Oleh karenanya dibutuhkan dukungan dari berbagai pihak dalam upaya pencegahan dan penularan Covid-19. Salah satunya melalui program Kuliah Kerja Nyata yang diselenggarakan oleh perguruan tinggi dan dilakukan secara mandiri oleh mahasiswa.Sebagai program intra kurikuler, KKN menjadi jembatan dalam mentransfer konsep teoritis ke dalam kehidupan praktik di masyarakat. Disamping sebagai salah satu upaya membantu pemerintah dalam pencegahan dan penularan Covid-19, tujuan dari KKN mandiri adalah agar mahasiswa dapat memperoleh pengalaman belajar serta memiliki keterlibatan untuk membantu masyarakat khususnya di lingkungan keluarga mereka sendiri, tempat tinggalnya dan masyarakat secara luas. Melalui pendampingan yang dilakukan bersama Dosen Pembimbing Lapangan, mahasiswa diminta untuk menyusun program kegiatan yang dapat menghasilkan output berupa edukasi kegiatan hingga produk. Output yang dihasilkan diharapkan menjadi langkah dalam mencegah penularan Covid-19. Adapun metode yang dilakukan ialah melalui bimbingan secara interaktif, Focus Group Discussion (FGD) antara dosen dan mahasiswa serta pendampingan. Hal ini dilakukan sebagai bagian dari kegiatan konsultasi dan pendampingan agar para mahasiswa yang melaksanakan KKN Mandiri dapat mencapai sasaran dan tujuan kegiatan.Selain itu, keberadaan aplikasi KKN bernama SIKANDO yang telah dirancang oleh pihak Universitas, diharapkan mampu menjadi alat monitoring selama KKN berlangsung. Adapun hasil yang dapat diperoleh dari kegiatan ini antara lain: dapat meningkatkan peran serta mahasiswa sebagai inovator sekaligus adanya bantuan pemikiran, tenaga serta ilmu pengetahuan yang dapat langsung diimplementasikan kepada masyarakat dalam upaya pencegahan penularan Covid-19.
\end{abstract}

Kata kunci: KKN mandiri, peran mahasiswa, inovasi, pencegahan covid-19

\begin{abstract}
The Covid-19 pandemic has provided various changes in all areas of life. Therefore, support is needed from various parties in efforts to prevent and spread Covid-19. One of them is through the Kuliah Kerja Nyata program organized by university and carried out independently by students in their respective neighborhoods. As an intracurricular program, KKN becomes a bridge in transferring theoretical concepts to practical life in society. Through mentoring carried out with Field Supervisors, students are asked to compile a program of activities that can produce output in the form of educational activities to products. The resulting output is expected to be a step in preventing transmission of Covid-19. The method used is interactive guidance, through Focus Group Discussions (FGD) and mentoring between lecturers and students. This is done as part of the consultation and assistance activities so that students who carry out KKN Mandiri can achieve the goals and objectives of the activity. Besides, the existence of the KKN application called SIKANDO which has been designed by the University is expected to be a monitoring tool during KKN
\end{abstract}

Keywords: innovation, KKN mandiri, student role, prevention of covid-19

To cite this article: Himawati, I. P., H. Nopianti., \& D. Widiyarti. 2020. Optimalisasi peran mahasiswa melalui kuliah kerja nyata mandiri sebagai upaya mendukung pencegahan penularan Covid-19 pada masyarakat. Unri Conference Series: Community Engagement 2: 379-385. https://doi.org/10.31258/unricsce.2.379-385

(c) 2020 Authors

Peer-review under responsibility of the organizing committee of Seminar Nasional Pemberdayaan Masyarakat 2020 


\section{PENDAHULUAN}

Pandemi Covid-19 telah memberikan dampak yang begitu signifikan di berbagai bidang kehidupan. Berdasarkan data dari Badan Pusat Statistik yang dilansir oleh www.kompas.com, pertumbuhan ekonomi Indonesia pada kuartal II tahun 2020 telah mengalami minus sebesar 5,32 persen. Aspek perekonomian mengalami kemerosotan hingga menyebabkan jumlah pengangguran mengalami peningkatan. Perubahan yang cukup signifikan dirasakan ialah penerapan aturan physical distancing hingga menyebabkan banyak aktivitas mengalami pembatasan. Banyak wilayah yang juga menerapkan karantina mandiri hingga melakukan Pembatasan Sosial Berskala Besar (PSBB). Di bidang pendidikan pun demikian adanya, perubahan sistem pembelajaran terasa begitu kentara, dari yang semula tatap muka lantas berubah menjadi pembelajaran daring dengan mengandalkan aplikasi pertemuan yang tersedia. Protokol kesehatan menjadi semacam aturan dan kebijakan baru yang perlu diadaptasi dalam menjalankan aktivitas di tengah pandemi. Kondisi ini telah mengisyaratkan beragam perubahan dan kontribusi masyarakat dari berbagai elemen masyarakat menjadi sebuah kebutuhan. Kontribusi dapat dilakukan dengan berbagai cara, mulai dari rasa empati, kepatuhan terhadap protocol kesehatan, menerapkan physical distancing secara bertanggung jawab, menghasilkan produk seperti vaksin serta berbagai perilaku dan aktivitas lainnya yang menunjang dalam penularan, pencegahan dan penanggulangan Covid-19.

Salah satu kontributor nyata dalam struktur masyarakat, diantaranya adalah mahasiswa. Mahasiswa merupakan individu yang memiliki peran strategis dalam merangsang adanya perubahan. Hal ini ditenggarai lantaran perannya sebagai agen perubahan yang tak lepas dalam memberikan stimulant melalui kreativitas dan inovasi yang dihasilkan dalam kehidupan. Peran ini pun semakin penting dalam upaya mendukung civitas akademika, dalam hal ini adalah dosen, dalam melaksanakan tridharma perguruan tinggi. Oleh karenanya berbagai peluang dalam upaya mendukung terlaksananya tridharma perguruan tinggi menjadi penting untuk dilakukan. Salah satunya melalui program Kuliah Kerja Nyata atau yang lebih dikenal dengan istilah KKN. Kegiatan ini diselenggarakan oleh Universitas Bengkulu dengan rentang waktu sekitar 37 hari. Sebagai program intra kurikuler, KKN menjadi jembatan dalam mentransfer konsep teoritis ke dalam kehidupan secara praktik. Adanya pandemi Covid-19 ini pun akhirnya menyebabkan KKN dilakukan secara mandiri di semua lini kehidupan. Para mahasiswa diminta untuk dapat mengaktualisasikan dirinya dalam mencegah serta menangani Covid 19 di wilayah masing-masing. Hal ini merupakan salah satu bentuk kontribusi nyata yang dapat dilakukan oleh mahasiswa selaku pelaku perubahan. Dalam prosesnya, mahasiswa jelas tidak sendiri, keberadaan dosen pembimbing lapangan, jelas memiliki peran penting dalam mendampingi mahasiswa sehingga dapat mengoptimalisasi perannya. Rangkaian bimbingan dan konsultasi sebagai upaya mengoptimalisasikan peran tersebut menjadi penting untuk dilakukan. Sehingga pelaksanaan Kuliah Kerja Nyata (KKN) meski bersifat mandiri, namun tetap dapat memberikan kontribusi, setidaknya di lingkungan terkecil tempat tinggal para mahasiswa tersebut. Kegiatan rutin $\mathrm{KKN}$ ini pun diharapkan dapat mendayagunakan mahasiswa baik dari segi pemikiran, tenaga serta ilmu pengetahuan agar terlibat langsung dalam menyelesaikan permasalahan yang muncul karena pandemic Covid-19 di lingkungan keluarga dan masyarakat tempat tinggalnya.

\section{METODE PENERAPAN}

Adapun upaya pemecahan masalah dalam kegiatan ini meliputi beberapa metode antara lain adalah sebagai berikut:

a. Bimbingan Secara Interaktif

Kegiatan ini dilakukan melalui penyelenggaraan penyuluhan secara interaktif melalui mekanisme ceramah sekaligus pelatihan dalam rangka mendistribusikan pengetahuan (transfer of knowledge) kepada para mahasiswa. Sehingga mahasiswa dapat mengetahui peran dan tugasnya selama menjalankan Kuliah Kerja Nyata. Adapun topik yang disampaikan dalam kegiatan ini adalah sebagai berikut:

\begin{tabular}{cl}
\hline No & \multicolumn{1}{c}{ Topik Penting } \\
\hline 1 & Pelatihan Penyusunan Proposal Kegiatan Kuliah Kerja Nyata \\
2 & Eksplorasi dan Elaborasi Kegiatan KKN yang Relevan di Wilayah Tempat Tinggal Mahasiswa \\
3 & Pelatihan Pengisian Diary dan Presensi Kegiatan Kuliah Kerja Nyata \\
4 & Pelatihan Penyusunan Laporan Kemajuan \\
5 & Pelatihan Penyusunan Laporan Akhir Kuliah Kerja Nyata \\
\hline
\end{tabular}




\section{b. FGD (Focus Group Discussion) Online}

Pada kegiatan Pengabdian Masyarakat yang dilakukan, salah satu metode yang digunakan adalah Focus Group Discussion secara online. Focus Group Discussion atau yang dikenal dengan FGD merupakan suatu bentuk diskusi yang dilakukan secara sistematis sekaligus terarah mengenai suatu isu atau masalah tertentu. Pada metode ini, upaya dialogis dan bertukar pikiran atas berbagai persoalan terjadi antara dosen pembimbing lapangan dengan mahasiswa. Dalam FGD ini, para mahasiswa diberikan kesempatan seluasluasnya untuk bertanya guna mendapatkan informasi dan pengetahuan secara mendalam.

c. Pendampingan

Salah satu metode yang dilakukan lainnya adalah pendampingan. Kegiatan pendampingan merupakan salah satu upaya yang dilakukan secara berkesinambungan selama proses kegiatan Kuliah Kerja Nyata dilakukan oleh mahasiswa. Upaya ini merupakan salah satu sarana dalam memberikan pengarahan agar proses kegiatan KKN dalam berjalan sesuai tujuan.

\section{HASIL DAN KETERCAPAIAN SASARAN}

Pengabdian masyarakat yang dilakukan ini merupakan upaya dalam mengoptimalisasi peran mahasiswa dalam pelaksanaan KKN Mandiri periode 91. Kegiatan pengabdian masyarakat ini diinisiasi oleh tim dosen yang juga sekaligus menjadi dosen pendamping lapangan. Masing-masing dosen mendampingi sekitar 2-3 kelompok KKN yang berbeda. Masing-masing kelompok terdiri dari sekitar 10 mahasiswa yang berasal dari berbagai jurusan dan program studi yang tersebar di Universitas Bengkulu. Para mahasiswa tersebut melangsungkan kegiatan KKN secara mandiri di tempat tinggal masing-masing. Adapun wilayah domisili mahasiswa tersebar di beberapa kabupaten kota yang ada di Provinsi Bengkulu maupun luar Bengkulu. Pada prosesnya, secara teknis, tim pengabdian masyarakat melibatkan beberapa mahasiswa yang berasal dari lintas jurusan dan fakultas untuk membantu pelaksanaan teknis di lapangan, misal membantu mengurus surat serta mengumpulkan berbagai dokumentasi selama kegiatan KKN berlangsung. Adapun nama-nama mahasiswa yang terlibat diantaranya adalah sebanyak 5 orang. Kelimanya merupakan mahasiswa yang berasal dari fakultas dan jurusan yang berbeda.

Kegiatan pendampingan diawali dengan pengenalan dari tiap anggota kelompok. Kegiatan pendampingan dan bimbingan selama kegiatan KKN Mandiri dilakukan secara daring, serta memanfaatkan aplikasi SIKANDO yang telah dirancang oleh Tim P3KKN universitas. Tim pengabdian masyarakat masing-masing mendapatkan sekitar 2-3 kelompok untuk didampingi. Setiap kelompok terdiri dari sekitar 10 orang mahasiswa yang berasal dari jurusan dan fakultas yang berbeda. Setelah proses pengenalan berlangsung, maka dilanjutkan dengan aktivitas pengajuan proposal program kegiatan yang dilakukan oleh mahasiswa. Pada kesempatan ini mahasiswa diminta untuk mengajukan program kegiatan dalam bentuk proposal. Proposal yang disusun hendaknya sesuai dengan panduan pelaksanaan Kegiatan KKN yang telah ditetapkan oleh P3KKN LPPM selaku penyelenggara kegiatan. Kemudian, proposal program yang diajukan dikoreksi oleh Dosen Pendamping Lapangan atau yang dikenal dengan istilah DPL KKN. 


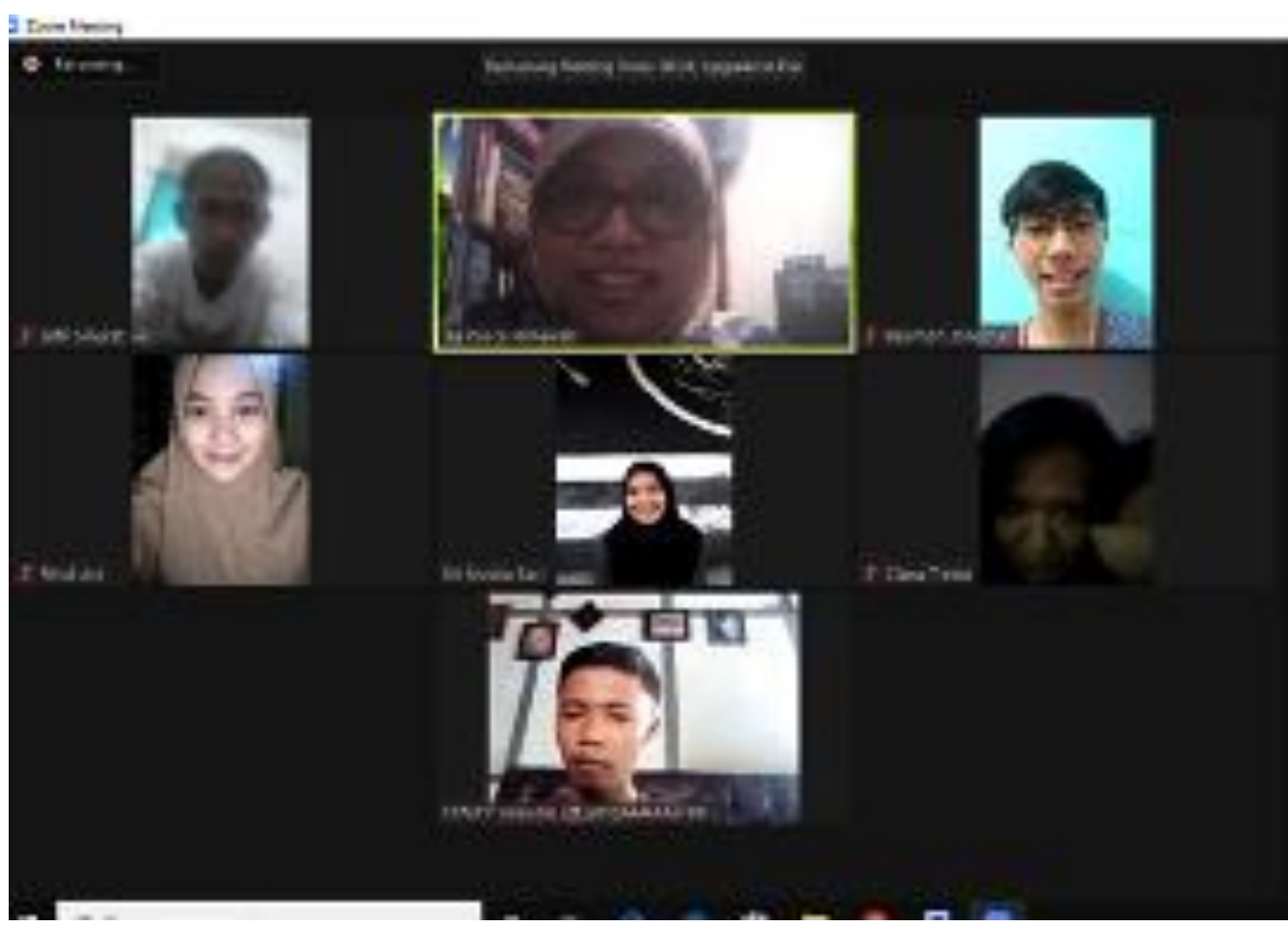

Gambar 1. Diskusi Antara DPL dan Mahasiswa Secara Daring Mengenai Proses Pelaksanaan Kegiatan KKN Mandiri (Sumber: Dokumentasi Tim PPM, 2020)

Setelah proposal program kegiatan disetujui, maka para mahasiswa dapat melanjutkan pelaksanaan program kegiatan secara berkesinambungan. Mahasiswapun diminta untuk dapat melakukan pengisian diary serta presensi secara harian melalui aplikasi yang telah dibuat bernama SIKANDO. Setiap minggunya mahasiswa diminta untuk melaporkan pelaksanaan program dalam bentuk laporan kemajuan. Setelah diperiksa dan disetujui oleh DPL KKN, maka mahasiswa dapat melanjutkan program yang telah disusun. Namun, apabila ada koreksi dan masukan dari DPL KKN, maka mahasiswa diminta untuk memperbaiki berdasarkan masukan yang diberikan. Mahasiswa Pun dapat menyampaikan kendala dan hambatan kepada DPL KKN, untuk kemudian dapat dicarikan solusi agar masalah tersebut dapat teratasi. Selama pelaksanaan program, guna memudahkan koordinasi, maka mahasiswa KKN membentuk grup Whatsapp di masing-masing kelompok. Di dalam grup tersebut, proses koordinasi berlangsung secara berkesinambungan. Mahasiswa diminta untuk melaporkan aktivitas dan produk yang dihasilkan setiap harinya, baik melalui aplikasi maupun grup whatsapp yang telah dibuat.Tiap minggu laporan kemajuan diupload melalui aplikasi SIKANDO. Pelaksanaan kegiatan KKN pun diselesaikan dengan adanya laporan akhir yang disusun oleh mahasiswa. Mahasiswa diminta untuk dapat membuat laporan akhir sesuai dengan petunjuk panduan KKN yang telah diberikan oleh P3KKN. Setelah melalui proses perbaikan, maka laporan akhir diupload serta mendapatkan persetujuan dari DPL KKN. 


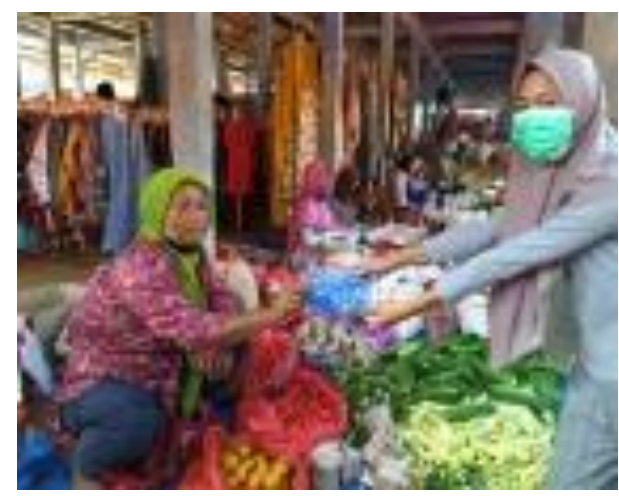

Mahasiswa membagikan masker ke masyarakat Sumber: Dokumentasi Mahasiswa KKN, 2020

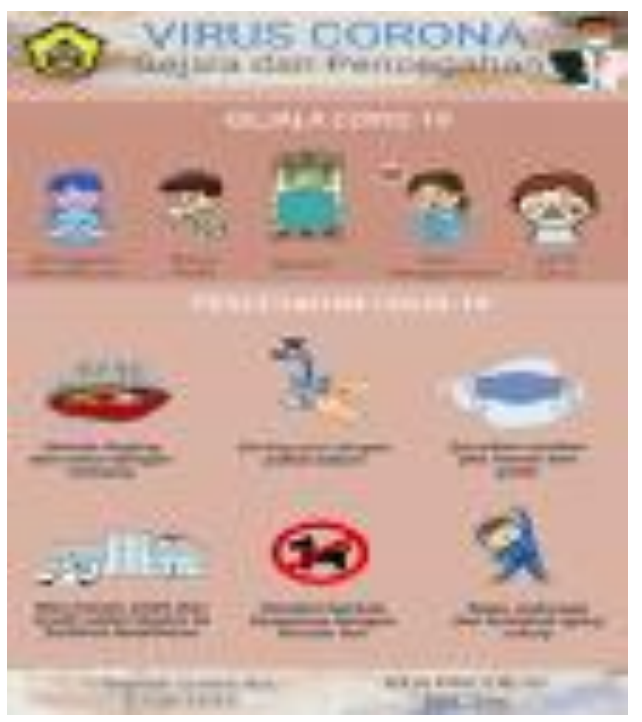

Mahasiswa membuat Poster untuk Dipublikasi Di Media Sosial

Sumber: Dokumentasi Mahasiswa KKN, 202

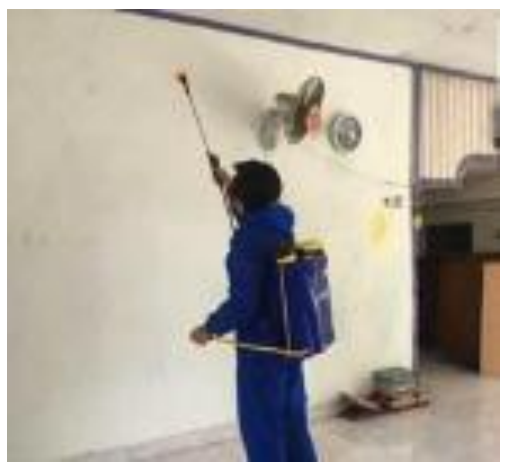

Mahasiswa melakukan penyemprotan disinfektan

Sumber: Dokumentasi Mahasiswa KKN, 2020

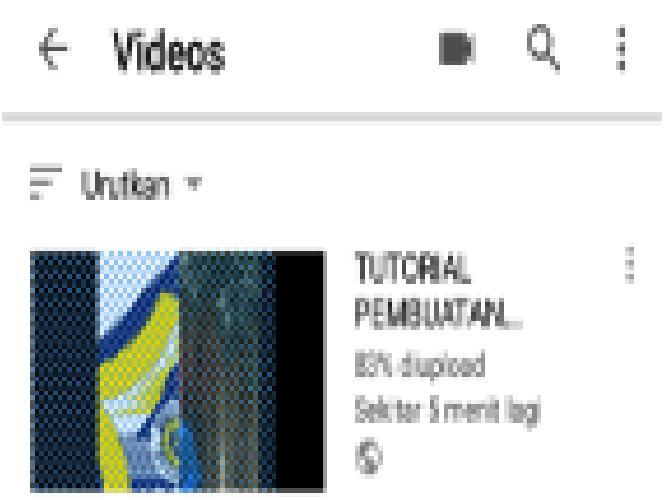

Pembuatan Video Tutorial Pembuatan Masker Oleh Mahasiswa

Sumber: Dokumentasi Mahasiswa KKN, 2020

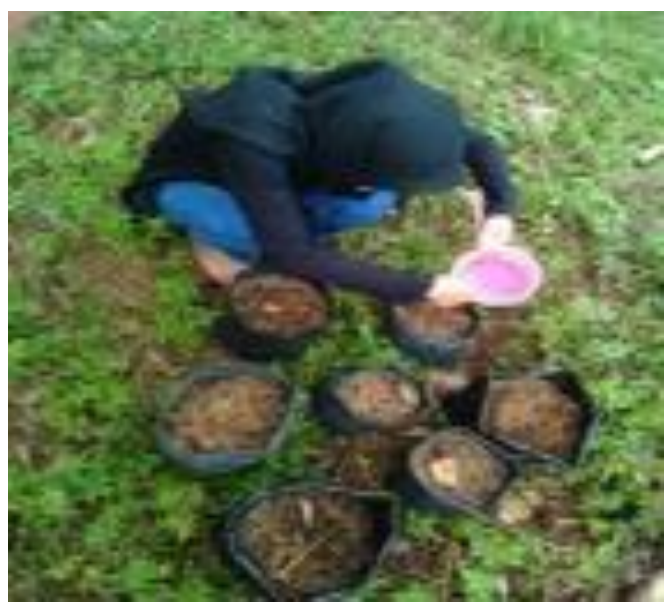

Mahasiswa menanam Sayuran di Pekarangan Rumah

Sumber: Dokumentasi Mahasiswa KKN, 2020

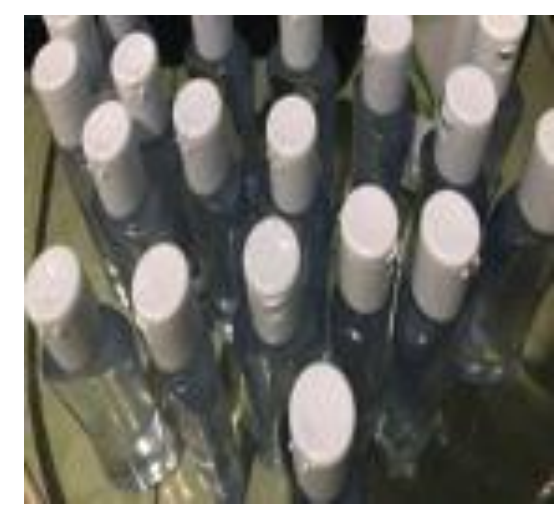

Mahasiswa membuat Hand Sanitizer Sumber: Dokumentasi Mahasiswa KKN, 2020 


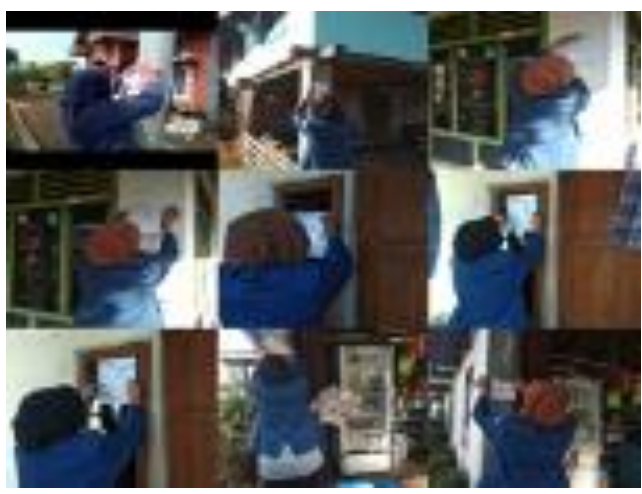

Mahasiswa menempelkan Poster Di Lokasi Publik

Sumber: Dokumentasi Mahasiswa KKN, 2020

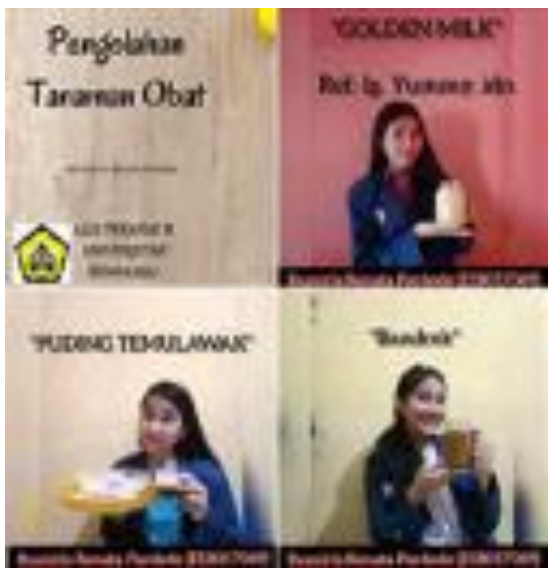

Mahasiswa membuat tutorial membuat TOGA Sumber: Dokumentasi Mahasiswa KKN, 2020

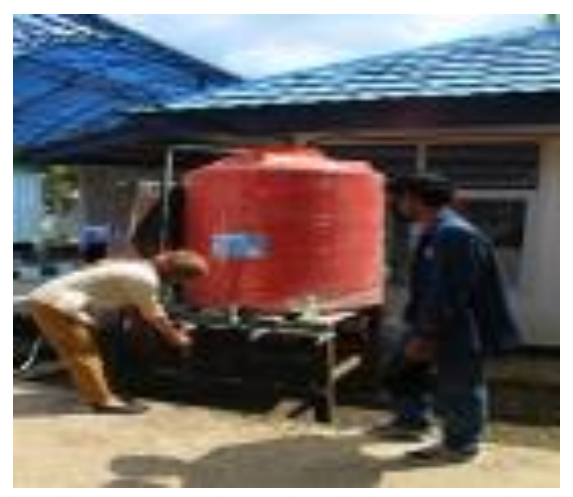

Mahasiswa mendampingi dan memberikan pengetahuan tentang cara mencuci tangan kepada warga

Sumber: Dokumentasi Mahasiswa KKN, 2020

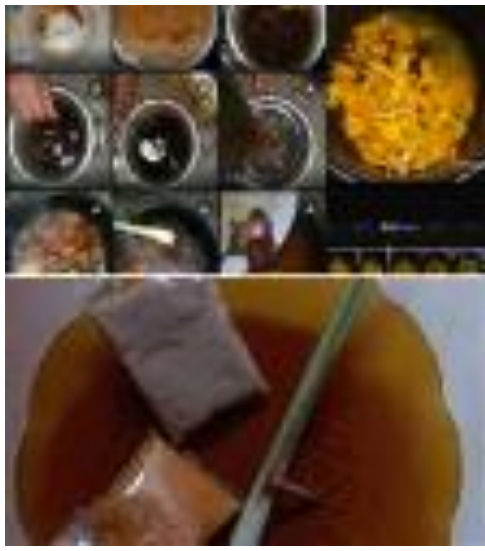

Diversifikasi tanaman TOGA

Sumber: Dokumentasi Mahasiswa KKN, 2020

Gambar 2. Hasil Kegiatan KKN Mandiri yang dilakukan oleh Mahasiswa

Adapun produk yang dihasilkan oleh Kelompok KKN Mandiri 91 yang didampingi oleh Tim Pengabdian masyarakat antara lain: Masker Kain, Hand Sanitizer otomatis, Video, Poster dan tulisan di Blog yang berisi edukasi seputar Covid-19, yang dipublikasikan ke media sosial, Hand Sanitizer Berbahan Alami dari Lidah buaya, Sirih dan Jeruk Nipis, Pemanfaatan pekarang rumah dengan tanaman sayur maupun TOGA, Diversifikasi tanaman TOGA menjadi bahan pangan dan lain sebagianya. Semua produk yang dihasilkan sebagian besar dibagikan kepada masyarakat yang berada di lingkungan tempat tinggal para mahasiswa peserta KKN mandiri. Disamping itu, mahasiswa pun ada yang melakukan penyemprotan disinfektan di lokasi sekitar rumah mereka masing-masing serta terlibat menjadi relawan penanganan Covid-19 di wilayah masing-masing.

\section{KESIMPULAN}

Optimalisasi peran mahasiswa melalui kuliah kerja nyata menjadi begitu penting untuk dilakukan. Tujuannya agar mahasiswa mampu berkontribusi dan berdaya guna dalam masyarakat. Peran sebagai agen of change yang disandang oleh mahasiswa dalam KKN mandiri yang dilakukan, diwujudkan melalui berbagai aktivitas yang dilakukan secara mandiri di kediaman masing-masing. Adapun aktivitas dan produk yang dihasilkan dituangkan ke dalam laporan akhir mahasiswa. Produk yang telah dihasilkan sebagian besar diberikan secara cuma-Cuma kepada masyarakat disekitar lingkungan tempat tinggal para mahasiswa tersebut. Sedangkan kegiatan yang bersifat edukasi dipublikasi secara langsung kepada masyarakat maupun secara tidak langsung melalui media sosial yang dimiliki. 


\section{DAFTAR PUSTAKA}

Martadinata, Arnan Muflihady. 2019. Peran Mahasiswa Dalam Pembangunan di Indonesia. IDEA: Jurnal Humaniora, 2(1), 1-6. https://ejournal.unisba.ac.id/index.php/idea/article/view/2435/pdf

P3KKN. 2020. Panduan dan Petunjuk Teknis Kuliah Kerja Nyata (KKN) Mandiri. Bengkulu: P3KKN LPPM

Suherman, S. Wawan. 2011. Pemberdayaan Masyarakat Melalui Kuliah Kerja Nyata. Yogyakarta: Kumpulan Makalah Pembekalan KKN UNY 2011, hal 21-29.

Syardiansyah. 2017. Peranan Kuliah Kerja Nyata Sebagai Bagian Dari Pengembangan Kompetensi Mahasiswa (Studi Kasus Mahasiswa Universitas Samudra KKN Tahun 2017). JIM UPB, 7(1), 57-68.

http://ejournal.upbatam.ac.id/index.php/jim/article/view/915

Universitas Gadjah Mada. 2020. Buku Saku Desa Tangguh. Yogyakarta: Universitas Gadjah Mada.

https://money.kompas.com/read/2020/08/05/120854826/pertumbuhan-ekonomi-ri-minus-532-persen-pada-kuartal-ii2020 diakses pada 22 September 2020 Pukul 04.46 WIB.

https://www.youtube.com/results?search_query=p3kkn+unib diakses pada 23 September 2020 Pukul 05.25 WIB. 